\title{
Glass transition and thermal stability of hard magnetic bulk $\mathrm{NdAlFeCo}$ metallic glass
}

\author{
Bing Chen Wei ${ }^{a, *}$, Wei Hua Wang ${ }^{a, b}$, Lei Xia ${ }^{c}$, Zhi Zhang ${ }^{b}$, De Qian Zhao ${ }^{b}$, \\ Ming Xiang Pan ${ }^{\mathrm{b}}$ \\ a National Microgravity Laboratory, Institute of Mechanics, Chinese Academy of Sciences, Beijing 100080, People's Republic of China \\ ${ }^{\mathrm{b}}$ Institute of Physics and Center for Condensed Matter Physics, Chinese Academy of Sciences, Beijing 100080, People's Republic of China \\ ${ }^{\mathrm{c}}$ Institute of Materials, Shanghai University, Shanghai 200072, People's Republic of China
}

Received 23 July 2001; received in revised form 24 October 2001

\begin{abstract}
Glass transition and thermal stability of bulk $\mathrm{Nd}_{60} \mathrm{Al}_{10} \mathrm{Fe}_{20} \mathrm{Co}_{10}$ metallic glass were investigated by means of dynamic mechanical thermal analysis (DMTA), differential scanning calorimetry (DSC), X-ray diffraction (XRD) and scanning electronic microscopy (SEM). The glass transition temperature, not revealed by DSC, is alternatively determined by DMTA via storage modulus $E^{\prime}$ and loss modulus $E^{\prime \prime}$ measurement to be $498 \mathrm{~K}$ at a heating rate of $0.167 \mathrm{~K} \mathrm{~s}^{-1}$. The calculated reduced glass transition temperature $\left(T_{\mathrm{g}} / T_{\mathrm{m}}\right)$ is 0.63 . The large value of $T_{\mathrm{g}} / T_{\mathrm{m}}$ of this alloy is consistent with its good glass-forming ability. The crystallization process of the metallic glass is concluded as follows: amorphous $\rightarrow$ amorphous + metastable FeNdAl phase $\rightarrow$ amorphous + primary $\delta$-FeNdAl phase $\rightarrow$ primary $\delta$-phase + eutectic $\delta$-phase $+\mathrm{Nd}_{3} \mathrm{Al}+\mathrm{Nd}_{3} \mathrm{Co}$. The appearance of hard magnetism in this alloy is ascribed to the presence of amorphous phase with highly relaxed structure. The hard magnetism disappeared after the eutectic crystallization of the amorphous phase. (C) 2002 Elsevier Science B.V. All rights reserved.
\end{abstract}

Keywords: Metallic glasses; Phase transformations; Hard magnetic; Glass transition

\section{Introduction}

A number of new metallic alloys with excellent glass forming ability have been developed in the last 10 years, and it permits the formation of large bulky ingots of metallic glass [1-3]. These bulk metallic glasses (BMGs) have considerable potential as advanced engineering materials due to their excellent processing capabilities of the undercooled liquid, improved wear resistance, high strength, good corrosion resistance and especially soft magnetism [4-8]. More recently, NdFeAl family metallic glasses of a diameter up to $12 \mathrm{~mm}$ with high coercivity have been reported [9]. The NdFeAl family is a special type, because it seems to be the only family of BMGs that does not exhibit any glass transition temperature $T_{\mathrm{g}}$ prior to crystalliza-

\footnotetext{
* Corresponding author. Tel.: + 86-10-8264-9198; fax: + 86-106261-5524.

E-mail address: weibc@imech.ac.cn (B.C. Wei).
}

tion temperatures $T_{\mathrm{x}}$ [10]. This is anomalous because other BMGs possess a wide supercooled liquid region $\left(\Delta T=T_{\mathrm{x}}-T_{\mathrm{g}}\right)$ [6]. Moreover, the hard magnetic properties of the glassy $\mathrm{Nd}-\mathrm{Fe}-\mathrm{Al}$ based alloys are also interesting in both scientific and practical viewpoints, as no structural anisotropy should exist in a glassy (disordered) packing of atoms. Consequently, Nd-based BMGs have received considerable attention. But most of the development has been on the magnetic properties of this novel BMGs [10-12]. There is much less information on detail study of the glass transition and crystallization process $[13,14]$, although these processes are important in understanding the stability of these glassy materials. In this work, $\mathrm{Nd}_{60} \mathrm{Al}_{10} \mathrm{Fe}_{20} \mathrm{Co}_{10} \mathrm{BMG}$ has been prepared by chill casting. The glass transition and thermal stability of this BMG are investigated by means of differential scanning calorimetry (DSC), dynamic mechanical thermal analysis (DMTA), X-ray diffraction (XRD) and scanning electron microscopy (SEM). The glass transition temperature and crystal- 
lization sequence of the $\mathrm{BMG}$ are determined. The result will be helpful to understand the reason for appearance of good glass forming ability and hard magnetism in Nd-based BMGs.

\section{Experimental procedure}

Ingots with compositions of $\mathrm{Nd}_{60} \mathrm{Al}_{10} \mathrm{Fe}_{20} \mathrm{Co}_{10}$ were prepared by arc melting from elemental $\mathrm{Nd}, \mathrm{Fe}, \mathrm{Al}$ and Co with a purity of $99.9 \%$ in a titanium-gettered argon atmosphere. Cylindrical specimens of about $3 \mathrm{~mm}$ in diameter and $50 \mathrm{~mm}$ in length were prepared from the ingots by die casting into a copper mold under argon atmosphere. The structure of the as-cast cylinder was characterized by XRD in a Siemens D5000 diffractometer using $\mathrm{Cu} \mathrm{K} \mathrm{K}_{\alpha}$ radiation. Thermal analysis was performed using a Perkin-Elmer DSC-7 differential scanning calorimeter under argon atmosphere. A heating rate of $0.167 \mathrm{~K} \mathrm{~s}^{-1}$ was applied. The dynamic mechanical properties were measured by using a dynamic mechanical thermal analyzer (DMTA IV) with three-point bending mode. In a viscoelastic solid, a sinusoidal strain is delayed from supplied sinusoidal stress by viscosity at an angle of $\delta$. Complex modulus $\left(E^{*}\right)$ is the ratio of maximum stress to maximum strain and the real and imaginary parts of $E^{*}$ were defined as storage $\left(E^{\prime}\right)$ and loss $\left(E^{\prime \prime}\right)$ modulus, respectively. $E^{\prime}$ is the value of the energy which is stored and recovered perfectly during one cycle of strain change, while $E^{\prime \prime}$ is the loss of energy which changes to heat during one cycle. The loss tangent $(\tan \delta)$ corresponds to the internal friction representing the degree of heat which was lost during one cycle. Generally, $E^{*}$ is calculated by $E=\left|E^{*}\right|=\sqrt{E^{\prime 2}+E^{\prime \prime 2}}$. When $E^{\prime} \gg E^{\prime \prime}$, the $E^{\prime}$ can be considered as $E^{*}$. In this investigation, the temperature dependence of the $E^{\prime}, E^{\prime \prime}$ and $\tan \delta$ was measured with

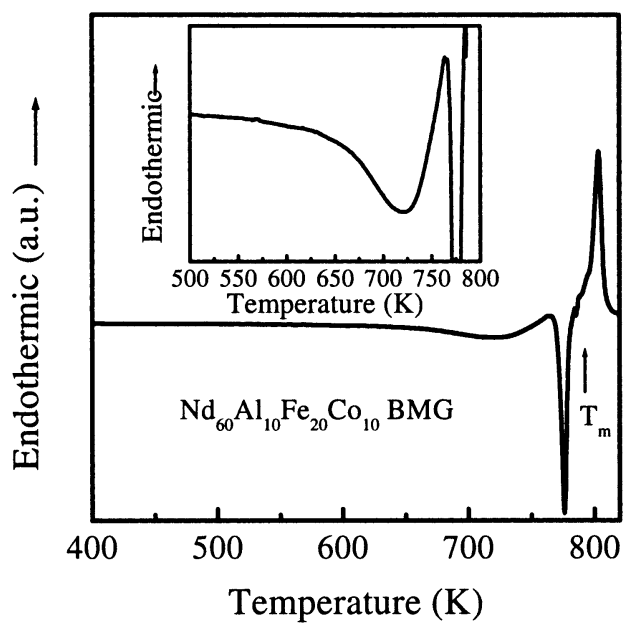

Fig. 1. DSC curve of the as-cast $\mathrm{Nd}_{60} \mathrm{Al}_{10} \mathrm{Fe}_{20} \mathrm{Co}_{10} \mathrm{BMG}$. The inset shows the enlarged part of the broad exothermic peak. samples of $1.2 \times 3.0 \times 30 \mathrm{~mm}^{3}$ in dimensions under dynamic conditions with a static load of $1 \mathrm{~N}$ at a frequency of $1 \mathrm{~Hz}$. Microstructure was studied by a Cambridge scanning electron microscope equipped with link energy dispersive X-ray (EDX) microanalysis system. Magnetic measurements were performed using a vibrating sample magnetometer (VSM) with a maximum applied field of $1592 \mathrm{kA} \mathrm{m}^{-1}$.

\section{Results and discussion}

The as-cast cylinder exhibits an XRD spectrum typical for amorphous phase without obvious crystalline reflection peaks. Fig. 1 shows the DSC curve of the as-cast $\mathrm{Nd}_{60} \mathrm{Al}_{10} \mathrm{Fe}_{20} \mathrm{Co}_{10}$ BMG. It exhibits two exothermic reactions, a lower temperature weak peak ranging from 642 to $754 \mathrm{~K}$ and a higher temperature sharp peak, followed by an endothermic reaction of melting. The obvious endothermic peak due to the glass transition is not observed in the trace, and this result is consistent with the others results on NdFeAl-based alloys $[10,12]$. The broad exothermic peak was also observed in previous work, but this exothermic reaction is still unclear. The sharp exothermic peak at higher temperature is caused by the marked crystallization. This also confirms the glassy structure of the as-cast sample.

Dynamic mechanical thermal analysis on the as-cast sample is shown in Fig. 2a. Starting from room temperature, initially the storage modulus $E^{\prime}$ decreases slightly as expected for conventional metals. The specimen softens markedly at $498 \mathrm{~K}$, and $E^{\prime}$ decreases rapidly from $48 \mathrm{MPa}$ at $498 \mathrm{~K}$ to $31 \mathrm{MPa}$ at $588 \mathrm{~K}$. Subsequently, $E^{\prime}$ shows a weak peak with an onset temperature of $588 \mathrm{~K}$, and then decreases continuously with the increase of temperature. The corresponding loss modulus $E^{\prime \prime}$ exhibits a large loss of energy above $498 \mathrm{~K}$ and shows a loss peak at $571 \mathrm{~K}$. The $E^{\prime \prime}$ curve shows the maximum value at $588 \mathrm{~K}$, which corresponds to the weak peak of $E^{\prime}$ curve. The temperature dependence of $\tan \delta$ (not shown here) is similar to that of $E^{\prime \prime}$. $E^{\prime \prime}$ corresponding to the heat loss caused by a thermally activated process such as diffusion shows a rapid increase in the temperature range from 498 to $571 \mathrm{~K}$, indicating that a remarkable transition occurs. In addition, the continuous increase of the $E^{\prime \prime}$ is accompanied by the rapid decrease of the $E^{\prime}$. This suggests the transition is a glass transition process with a onset temperature of $498 \mathrm{~K}$, which leads to the notable softening of the alloy. In order to confirm this opinion, DMTA measurement of the $\mathrm{Nd}_{60} \mathrm{Al}_{10} \mathrm{Fe}_{20} \mathrm{Co}_{10}$ BMG annealed at $538 \mathrm{~K}$ (above $498 \mathrm{~K}$ ) for $1.2 \mathrm{ks}$ was carried out (Fig. 2b). The significant change of $E^{\prime}$ above $498 \mathrm{~K}$ and $E^{\prime \prime}$ peak similar to that of the as-cast samples is also observed. This confirms that the transition is a reversible course. 


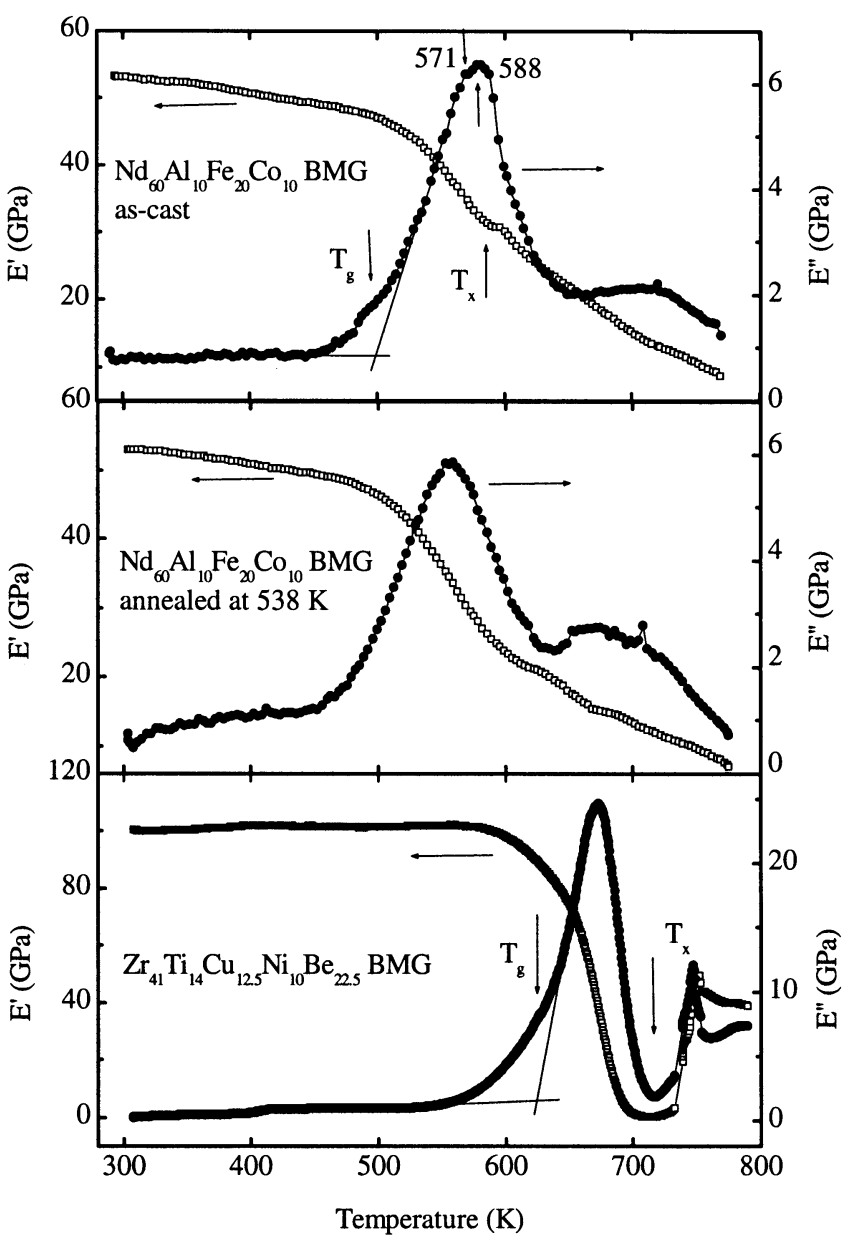

Fig. 2. Temperature dependence of storage modulus $E^{\prime}$ and loss modulus $E^{\prime \prime}$ of: (a) as-cast $\mathrm{Nd}_{60} \mathrm{Al}_{10} \mathrm{Fe}_{20} \mathrm{Co}_{10} \quad$ BMG; (b) $\mathrm{Nd}_{60} \mathrm{Al}_{10} \mathrm{Fe}_{20} \mathrm{Co}_{10}$ BMG annealed at $603 \mathrm{~K}$; and (c) as-cast $\mathrm{Zr}_{41} \mathrm{Ti}_{14} \mathrm{Cu}_{12.5} \mathrm{Ni}_{10} \mathrm{Be}_{22.5} \mathrm{BMG}$

Moreover, the temperature range of the $E^{\prime \prime}$ peak is much higher than the Curie temperature $(462 \mathrm{~K})$ of the $\mathrm{BMG}$, so the reversible transition above $498 \mathrm{~K}$ is not a ferromagnetic transition. Comparative DMTA test was also conducted on $\mathrm{Zr}_{41} \mathrm{Ti}_{14} \mathrm{Cu}_{12.5} \mathrm{Ni}_{10} \mathrm{Be}_{22.5}$ BMG with a distinct glass transition at $623 \mathrm{~K}$, which is determined by DSC measurement with a heating rate of 0.167 $\mathrm{K} \mathrm{s}^{-1}$. The results are shown in Fig. 2c. It can be seen that similar rapid decrease of $E^{\prime}$ and remarkable loss of energy during glass transition were also observed. Previous studies of Chen et al. on dynamic mechanical properties of metallic glass shows that the mechanical properties decrease greatly near the glass transition temperature [15]. Anderson et al. reported that the glass transition temperatures measured by viscous flow measurement agree well with DSC results [16]. The DMTA method uses the onset of viscoelastic damping due to the rapid decrease of viscosity above $T_{\mathrm{g}}$ and is therefore based on the same property change as the viscosity measurement [17]. Depending on the above analysis, we confirm that the distinct transition of the BMG above $498 \mathrm{~K}$ is a glass transition.

It is worth noting that the $E^{\prime}$ value for the $\mathrm{Zr}_{41} \mathrm{Ti}_{14} \mathrm{Cu}_{12.5} \mathrm{Ni}_{10} \mathrm{Be}_{22.5}$ sample is almost zero before crystallization, while it is still a relatively high value for the $\mathrm{Nd}_{60} \mathrm{Al}_{10} \mathrm{Fe}_{20} \mathrm{Co}_{10} \mathrm{BMG}$. The reason for this important difference is supposed to be that the present Ndbased BMG is a XRD amorphous, but not a fully amorphous like $\mathrm{Zr}_{41} \mathrm{Ti}_{14} \mathrm{Cu}_{12.5} \mathrm{Ni}_{10} \mathrm{Be}_{22.5}$ BMG. In fact, a large number of nano-scaled crystals, not resolved by XRD, but have been observed by transition electronic microscopy (TEM) in the as-cast $\mathrm{Nd}-\mathrm{Fe}$ based BMGs and even in melt-spinning ribbons [10,12]. The presence of these nano-crystals greatly increases the viscosity and modulus of the supercooled liquid. It must be pointed out that the notable glass transition exhibited in the DMTA results is not observed in the DSC curve in the same temperature range. The reason for this very weak thermal effect is probably that the glass transition takes place rather gradually in $\mathrm{Nd}-\mathrm{Fe}$ system due to the presence of a wide distribution of the composition in the amorphous phase. This is supported by the recent study of the magnetization-temperature relationship in $\mathrm{Nd}-\mathrm{Fe}$ based $\mathrm{BMG}$, in which a rather broad and clear magnetic transition was observed from 10 to $80 \mathrm{~K}$, suggesting the probably presence of amorphous phase with a wide composition range [18].

The weak peak of $E^{\prime}$ value in Fig. $2 \mathrm{a}$ at $588 \mathrm{~K}$ and the corresponding sharp $E^{\prime \prime}$ peak of the as-cast sample indicate that certain crystallization reaction occurs at this temperature, and causes the sudden increase of the viscosity of the supercooled liquid. The $E^{\prime}$ peak and loss energy peak due to crystallization are also observed in the DMTA curves of $\mathrm{Zr}_{41} \mathrm{Ti}_{14} \mathrm{Cu}_{12.5} \mathrm{Ni}_{10} \mathrm{Be}_{22.5} \mathrm{BMG}$ as shown in Fig. 2c. However, the magnitude of the increase of $E^{\prime}$ due to crystallization in $\mathrm{Nd}_{60} \mathrm{Al}_{10}$ $\mathrm{Fe}_{20} \mathrm{Co}_{10}$ BMG is much smaller than that in $\mathrm{Zr}_{41} \mathrm{Ti}_{14} \mathrm{Cu}_{12.5} \mathrm{Ni}_{10} \mathrm{Be}_{22.5}$ BMG (Fig. 2c). It can be inferred that the volume fraction of the crystalline phase precipitated at around $588 \mathrm{~K}$ has quite a small value. In the temperature range from 642 to $754 \mathrm{~K}$, the $E^{\prime \prime}$ curve in Fig. 2a shows a broad peak, which corresponds to the broad exothermal reaction in DSC curve in same temperature range (Fig. 1). This means that certain phase transition occurs, and this phase transition does not significantly change the $E^{\prime}$ value of the BMG as shown in Fig. 2a.

The XRD results of the isothermal annealed $\mathrm{Nd}_{60} \mathrm{Al}_{10} \mathrm{Fe}_{20} \mathrm{Co}_{10}$ are shown in Fig. 3. Annealing at 643 $\mathrm{K}$ for $1.8 \mathrm{ks}$ results in the appearance of unknown metastable phases, which transform into an equilibrium phase after annealing at $723 \mathrm{~K}$. The back scattering electron (BSE) image shows that no obvious compositional contrast is seen in the as-cast sample (Fig. 4a). The unknown metastable phases in the sample annealed at $643 \mathrm{~K}$ are dark, rod-like granules with a $\mathrm{Fe}: \mathrm{Nd}: \mathrm{Al}$ ratio of $75: 16: 9$ as shown in Fig. $4 \mathrm{~b}$. The volume 


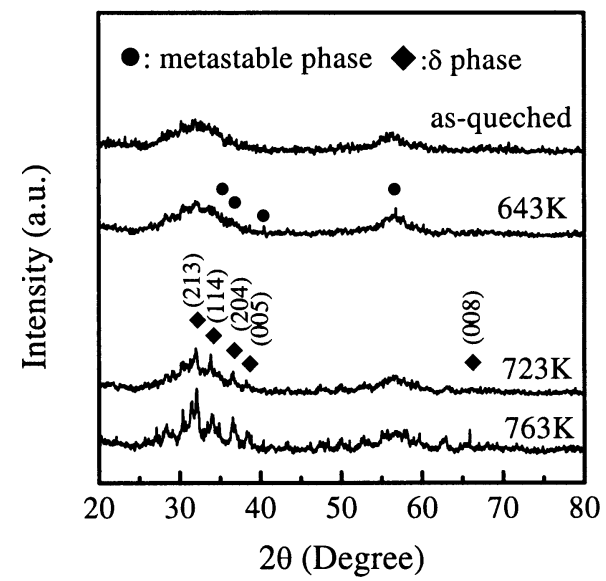

Fig. 3. Results of XRD for $\mathrm{Nd}_{60} \mathrm{Al}_{10} \mathrm{Fe}_{20} \mathrm{Co}_{10}$ annealed at different temperatures for $1.8 \mathrm{ks}$.

fraction of the metastable phase is estimated to be about $8.2 \%$ by calculating the difference of the crystallization enthalpy between as-cast sample and the sample annealed at $643 \mathrm{~K}$ for $1800 \mathrm{~s}$. This result suggests that the weak $E^{\prime}$ peak at $588 \mathrm{~K}$ in Fig. 2a is caused by the precipitation of metastable $\mathrm{FeNdAl}$ phase, which is not resolved by the DSC measurement due to its small quantity. The structure of this metastable FeNdAl ternary phase is under investigation. After annealing at $723 \mathrm{~K}$, the BSE results show that, the rod-like metastable phase is disappeared. Instead, a plate-like stable phase distributes in the remaining amorphous matrix as shown in Fig. 4c. The EDX results show that, this phase contains less $\mathrm{Fe}$, and its $\mathrm{Fe}: \mathrm{Nd}: \mathrm{Al}$ ratio is 49:34:17. This composition is close to the composition range of the $\delta$-phase $\left(\mathrm{Fe}_{67.5-x} \mathrm{Al}_{x} \mathrm{Nd}_{32.5}, 7<x<25\right)$, which is hexagonal with antiferromagnetism [19-21]. The XRD and SEM results show that the broad peak in the loss modulus and DSC curves in the temperature range from 642 to $754 \mathrm{~K}$ is caused by the transition from metastable $\mathrm{FeNdAl}$ phase to primary $\delta$-FeNdAl ternary phase. The BSE image of the $\mathrm{Nd}_{60} \mathrm{Al}_{10} \mathrm{Fe}_{20} \mathrm{Co}_{10}$ annealed at $763 \mathrm{~K}$ show that the structure consists of primary $\delta$ plus eutectic phases as shown in Fig. $4 d$. The EDX results show the eutectic consists of the thin plate-like eutectic $\delta$, dark $\mathrm{Nd}_{3} \mathrm{Al}$, and bright $\mathrm{Nd}_{3} \mathrm{Co}$. This structure is similar to the ternary $\mathrm{NdAlFe}$ eutectic $[19,20]$. This result means that the sharp exothermic peak in the DSC trace is attributed to eutectic crystallization of the remaining amorphous.

According to the above results, the reduced glass transition temperature $T_{\mathrm{rg}}$, termed as the ratio between $T_{\mathrm{g}}$ and melting point $T_{\mathrm{m}}$, of the studied alloy is calculated to be 0.63 , and the supercooled liquid region $\Delta T$ is $90 \mathrm{~K}$. The large value of $T_{\mathrm{rg}}$ and $\Delta T$ of this alloy is in consistent with its good glass-forming ability.

The dependence of $H_{\mathrm{c}}, M_{\mathrm{s}}$ and $M_{\mathrm{r}}$ on isothermal annealing temperature for $\mathrm{Nd}_{60} \mathrm{Al}_{10} \mathrm{Fe}_{20} \mathrm{Co}_{10}$ alloy is shown in Fig. 5. The results show that the as-cast $\mathrm{Nd}_{60} \mathrm{Al}_{10} \mathrm{Fe}_{20} \mathrm{Co}_{10}$ BMG exhibits hard magnetic behavior with a coercivity of $326 \mathrm{kA} \mathrm{m}^{-1}$. The hard magnetic properties remain almost unchanged in the annealing temperature range up to $743 \mathrm{~K}$ below the eutectic crystallization temperature determined by above analysis. This indicates that the precipitation and growth of the unknown metastable FeNdAl phase and the primary $\delta$-FeNdAl phase did not greatly change the magnetic properties of $\mathrm{Nd}_{60} \mathrm{Al}_{10} \mathrm{Fe}_{20} \mathrm{Co}_{10}$ glass, and the completely crystallization results in the disappearing of hard magnetic properties. It has been reported that a metastable $\mathrm{Nd}_{5} \mathrm{Fe}_{17}$ phase was responsible for the high coercivity in melt-spun binary $\mathrm{Nd}-\mathrm{Fe}$ ribbons [22]. However, this phase was not found in our samples. The $\delta$-phase is antiferromagnetic with a Neel temperature of approximately $260 \mathrm{~K}[19,21]$. The magnetic properties
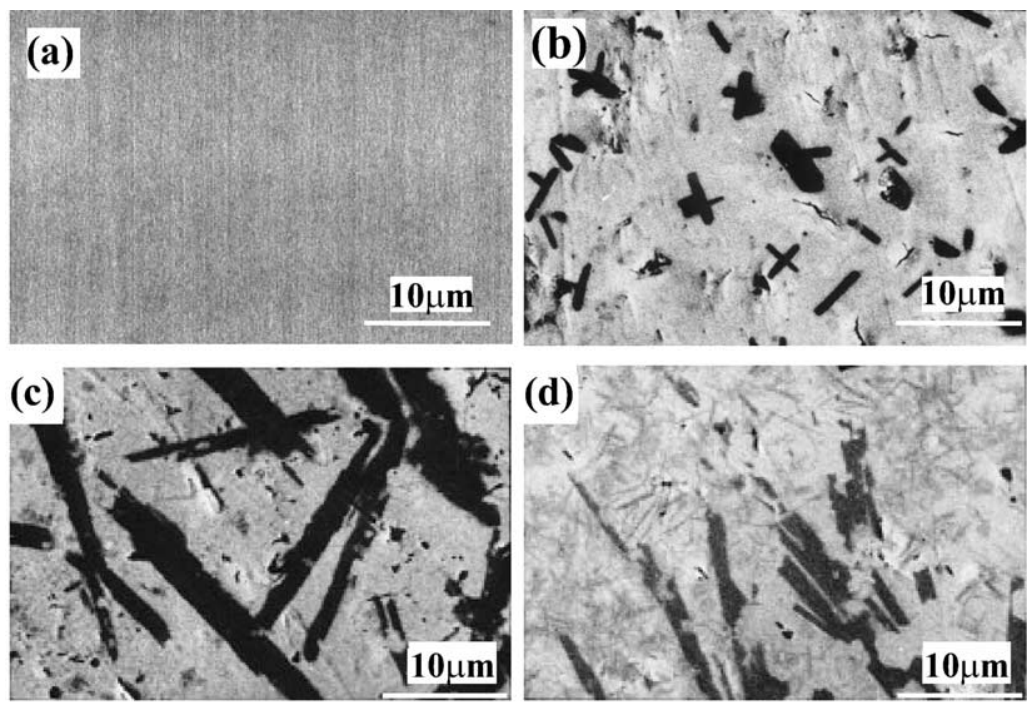

Fig. 4. BSE images of $\mathrm{Nd}_{60} \mathrm{Al}_{10} \mathrm{Fe}_{20} \mathrm{Co}_{10}$ annealed at different temperatures for 1.8 ks: (a) as-cast; (b) $643 \mathrm{~K}$; (c) $723 \mathrm{~K}$; and (d) $763 \mathrm{~K}$. 


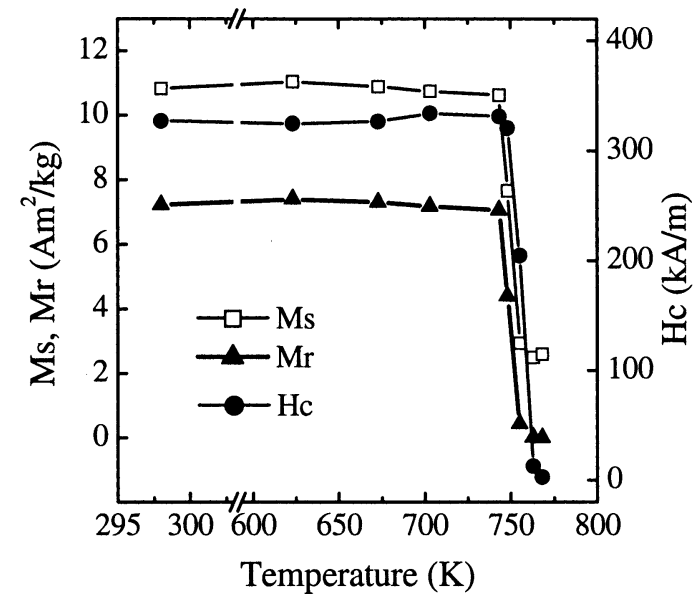

Fig. 5. Dependence of $H_{\mathrm{c}}, M_{\mathrm{s}}$ and $M_{\mathrm{r}}$ on isothermal annealing temperature for $\mathrm{Nd}_{60} \mathrm{Al}_{10} \mathrm{Fe}_{20} \mathrm{Co}_{10}$ alloy (annealing for $1.8 \mathrm{ks}$ ).

of the metastable FeNdAl are thought to be antiferremagnetic or paramagnetic. These indicate that the high coercivity in the NdAlFeCo alloy is due to the presence of the amorphous phase. Our results support the previously proposed ferromagnetic cluster model with large random anisotropy, and it shows that the high coercivity is attributed to the development of the homogeneous dispersion of the $\mathrm{Fe}(\mathrm{Co})$-rich clusters with large local magnetic anisotropy from the highly relaxed disordered structure developed at a cooling rate of about $10^{1}-10^{2} \mathrm{~K} \mathrm{~s}^{-1}$, which is much slower than the cooling rate of $10^{4}-10^{6} \mathrm{~K} \mathrm{~s}^{-1}$ in conventional spun-melt method [23]. No distinct low temperature relaxation transition is found in both DSC and DMTA curves of the as-cast sample, and it confirms the relaxed structure of $\mathrm{Nd}_{60} \mathrm{Al}_{10} \mathrm{Fe}_{20} \mathrm{Co}_{10}$ BMG.

\section{Conclusions}

In conclusion, the glass transition temperature of $\mathrm{Nd}_{60} \mathrm{Al}_{10} \mathrm{Fe}_{20} \mathrm{Co}_{10}$ BMG is determined by DMTA to be around $498 \mathrm{~K}$ at heating rate of $0.167 \mathrm{~K} \mathrm{~s}^{-1}$. The calculated $T_{\mathrm{g}} / T_{\mathrm{m}}$ shows a high value of 0.63 , which is consistent with the good glass-forming ability of this alloy. The crystallization process of this BMG is concluded as follows: amorphous $\rightarrow$ amorphous + metastable FeNdAl phase $\rightarrow$ amorphous + primary $\delta$-FeNdAl phase $\rightarrow$ primary $\delta$-phase + eutectic $\delta$ phase $+\mathrm{Nd}_{3} \mathrm{Al}+\mathrm{Nd}_{3} \mathrm{Co}$. The precipitation and growth of the metastable $\mathrm{FeNdAl}$ and the primary $\delta$-phase have no significant effect on the magnetic properties of the $\mathrm{Nd}_{60} \mathrm{Al}_{10} \mathrm{Fe}_{20} \mathrm{Co}_{10}$ glass.

\section{Acknowledgements}

The authors are grateful to the financial support of the National Natural Science Foundation of China (grant No. 50101012 and 59925101).

\section{References}

[1] A. Inoue, T. Zhang, T. Masumoto, Mater. Trans. JIM 31 (1990) 425.

[2] A. Inoue, T. Zhang, N. Nishiyama, K. Ohba, T. Masumoto, Mater. Trans. JIM 33 (1992) 937.

[3] A. Peker, W.L. Johnson, Appl. Phys. Lett. 63 (1993) 2342.

[4] W.L. Johnson, Mater. Sci. Forum 225-227 (1996) 35.

[5] T.G. Nieh, T. Mukai, C.T. Liu, J. Wadsworth, Scripta Mater. 40 (1999) 1021.

[6] A. Inoue, Acta Mater. 48 (2000) 279.

[7] A. Inoue, T. Zhang, A. Takeuchi, Appl. Phys. Lett. 71 (1997) 58.

[8] W.H. Wang, Q. Wei, M.P. Macht, S. Friedrich, H. Wollenberger, Appl. Phys. Lett. 71 (1997) 1053.

[9] A. Inoue, T. Zhang, A. Takeuchi, W. Zhang, Mater. Trans. JIM 37 (1996) 636.

[10] A. Inoue, A. Takeuchi, T. Zhang, Metall. Mater Trans. 29A (1998) 1779.

[11] G.J. Fan, W. Loser, S. Roth, J. Eckert, L. Schultz, Appl. Phys. Lett. 75 (1999) 2984.

[12] X.Z. Wang, Y. Li, J. Ding, L. Si, H.Z. Kong, J. Alloys Compd. 290 (1999) 209.

[13] Y. Li, S.C. Ng, Z.P. Lu, Y.P. Feng, K. Lu, Philos. Mag. Lett. 78 (1998) 213.

[14] B.C. Wei, Y. Zhang, Y.X. Zhuang, D.Q. Zhao, M.X. Pan, W.H. Wang, W.R. Hu, J. Appl. Phys. 89 (2001) 3529.

[15] H.S. Chen, N. Morito, J. Non-Cryst. Solids 72 (1985) 287.

[16] P.M. Anderson III, A.E. Lord Jr., Mater. Sci. Eng. 43 (1980) 267.

[17] R. Rambousky, M. Moske, K. Samwer, Mater. Sci. Forum 179-181 (1995) 761.

[18] R.J. Ortega-Hertogs, A. Inoue, K.V. Rao, Scripta Mater. 44 (2001) 1333.

[19] B. Grieb, E.-Th. Henig, G. Martinek, H.H. Stadelmaier, G. Petzow, IEEE Trans. Magn. 26 (1990) 1367.

[20] V. Pierre, Handbook of Ternary Alloy Phase Diagrams, ASM International, Materials Park, OH, 1994, p. 3525 and 3052.

[21] J. Ding, L. Si, Y. Li, X.Z. Wang, Appl. Phys. Lett. 75 (1999) 1763.

[22] H.H. Stadelmaier, G. Schneider, E. Henig, M. Ellner, Mater. Lett. 10 (1991) 303.

[23] K. Nagayama, H. Ino, N. Sato, Y. Nakagawa, E. Kita, K. Siratori, J. Phys. Soc. Jpn. 59 (1990) 2483. 